\title{
MÁS ALLÁ DE LA CASA Una mirada sobre el habitar desde las movilidades cotidianas
}

\author{
Arq. Jael Bengualid \\ Pertenencia institucional : CEUR CONICET INVIHAB FAUD UNC \\ Directora : Dra. Arq. Cecilia Marengo \\ jael_bngld@icloud.com
}

\section{RESUMEN}

El objetivo de la ponencia es la incorporación de una perspectiva de movilidad a una investigación sobre el habitar en el contexto de barrios cerrados. Por su carácter cotidiano, la movilidad articula otros espacios y temporalidades que pasaban inadvertidos desde un análisis anclado en la vivienda. Así nace la pregunta ¿dónde y cómo se debe buscar el sentido de la experiencia del habitar? Las implicaciones de las movilidades buscan contribuir al debate teórico-metodológico sobre lo urbano, poniendo énfasis en la perspectiva de los actores abordándolos etnográficamente a través del análisis de un caso en la ciudad de Córdoba. Se tienen en cuenta tanto los discursos y el plano de las representaciones, como las prácticas de los habitantes. Se propone develar parte de la dimensión experiencial de la ciudad y reconstruir la perspectiva del habitante para reflexionar sobre cómo sus dimensiones espacio-temporales se imbrican y cobran significados a partir de las prácticas cotidianas.

Palabras clave: movilidad - vida cotidiana - habitar - abordaje etnográfico

\begin{abstract}
This paper aims to the incorporation of a mobility perspective to an investigation about inhabiting in the context of gated communities. Because of its daily nature, mobility articulates other spaces and temporalities that went unnoticed from an analysis anchored in the home. This is how the question arises: where and how should we look for the meaning of the experience of inhabiting? The implications of the mobility seek to contribute to the theoretical-methodological debate on the urban sciences, putting emphasis on the actors' perspective, with an ethnographic approach through the analysis of one case in the city of Córdoba. It is proposed to unveil part of the experiential dimension of the city and reconstruct the perspective of the inhabitant to reflect on how its spatial and temporal dimensions overlap and take on meaning from everyday practices.
\end{abstract}

Key words: mobility - dwelling - daily life - ethnographic approach 


\section{INTRODUCCIÓN. LA IMPORTANCIA DE LA MOVILIDAD URBANA COTIDIANA Y DE SUS SUJETOS}

El presente texto se basa en la experiencia de investigación llevada a cabo en la ciudad de Córdoba, cuyo objetivo es la reflexión teórica y el estudio empírico en torno a las prácticas y experiencias de movilidad en la misma ciudad. Se realizan una serie de reflexiones de orden teórico, se presenta el esquema metodológico seguido y se presenta el análisis de uno de los casos.

Se explora con especial énfasis en las posibilidades que brinda la incorporación de una perspectiva de movilidad para develar dimensiones de la experiencia del habitar que, si mantuviésemos el foco solamente en la vivienda, pasarían inadvertidas. Por otro lado, indaga cómo esta serie de procesos de producción espacial se incorporan, son vividos, significados en las prácticas cotidianas de habitar desde la movilidad.

Cuando hablamos de prácticas nos referimos a los distintos modos de hacer que las personas desarrollamos en nuestras vidas cotidianas, permitiéndonos establecer relaciones sociales y configurar el espacio habitado. El carácter cotidiano de las prácticas alude a aquellas condiciones diarias de vida. Como ya lo plantearon autores como Lefebvre (1972) y De Certeau (1996), reconocer la importancia de la cotidianeidad en las prácticas sociales de los habitantes urbanos permite explorar aquellos aspectos invisibles y muchas veces problemáticos del habitar urbano, ignorados casi siempre por quienes toman decisiones sobre intervenciones urbanas en el territorio. De hecho, García Canclini (1997: 135) reflexionaba sobre la importancia de los desplazamientos urbanos como un tipo de recorrido donde se organiza gran parte del sentido común que la ciudad tiene para los sujetos.

Durante las últimas décadas ha comenzado a crecer el interés sobre la movilidad urbana cotidiana como uno de los componentes fundamentales para el funcionamiento de las urbes. Paola Jirón et. al (2010: 24) la define como "aquella práctica social de desplazamiento diario a través del tiempo y espacio urbano que permite el acceso a actividades, personas y lugares". Entonces, la movilidad urbana, entendiéndola como práctica, permite a los habitantes de las ciudades poder desarrollar sus actividades diarias y acceder a los recursos y posibilidades de los espacios urbanos morfológica, funcional y simbólicamente diferenciados y, de esta forma, integrarse y participar de la vida social, política y económica de la ciudad.

Sin embargo, la movilidad no tiene un rol meramente funcional. También da una oportunidad de poder observar otros aspectos presentes en la definición de Jirón, implicando, por un lado, reconocer la movilidad como fuente de experiencias particulares y diversas que cuestionan la idea de ciudad como una totalidad integrada y homogénea, arrojando luz sobre los distintos modos de habitar la metrópoli, develando la necesidad de incorporar las perspectivas de las personas. Por el otro, surge como oportunidad para interpretar cómo se usa y se apropia el espacio urbano en el ejercicio de la ciudadanía.

Esto es relevante, teniendo en cuenta que se trabaja con personas que viven en barrios cerrados quienes muchas veces, son pensados como si su presencia en el resto de la ciudad se construyera de una manera ambulante, participando de ella de manera errante, provisional y momentánea. Considerar la emergencia del "transeúnte" como un nuevo agente activo de la vida urbana (Imilan, 2007; Jirón, 2012; Imilan y Lange, 2003) cuestiona la correspondencia axiomática entre identidad, cultura y territorio usualmente utilizada en ciencias sociales.

Teniéndola en cuenta de esta manera, la movilidad urbana cotidiana admite repensar los debates desarrollados en la actualidad en el urbanismo y en las ciencias humanas, así como su inclusión en pensar los modos de habitar contemporáneos. Para ello, se reconceptualiza el lugar como también móvil dentro de la práctica de la movilidad cotidiana urbana propuesta por Jirón a través de relatos etnográficos que van estableciendo lugares en movimiento, acompañados por dibujos e imágenes fotográficas que dan cuenta de las apropiaciones espacio-temporales de movilidad de los habitantes urbanos de la ciudad de Córdoba. 


\section{LA EXPERIENCIA DEL HABITAR DESDE LA MOVILIDAD}

Mirar el habitar implica siempre asumir una concepción de espacio más vivencial y dejar de pensarlo como una suerte de escenario que soporta el transcurrir de la vida de las personas. Entonces, el espacio, en cuanto algo vivido, experimentado (Lefebvre, 1992), brota a partir de las prácticas (De Certeau, 1996). Implica que el espacio nunca es dado, sino que está en un constante devenir a partir de un mapa discursivo y de una práctica corporal. Desde esta perspectiva, el espacio del que hablamos se está construyendo permanentemente tanto con el cuerpo, en cuanto a inscripción y extensión de su entorno, como en las significaciones discursivas que lo hacen consciente. Es decir, podemos delimitar físicamente un lugar, pero no es espacio hasta que se da una práctica de ocupación activa por parte de las personas, hasta que se producen movimientos a través y alrededor de él. La espacialidad se produce en la articulación de prácticas de permanencia y de movilidad, entre raíces y rutas.

James Clifford, quien con un juego de palabras entre raíces (roots) y rutas (routes), reflexiona cómo siempre se considera a la residencia como el basamento y la localidad de la vida y el viaje como su suplemento. En consecuencia, las raíces siempre tienen una existencia previa a las rutas. Sin embargo, se pregunta:

“¿qué pasaría (...) si el viaje fuera visto sin trabas, como un espectro complejo y abarcador de las experiencias humanas? Las prácticas de desplazamiento podrían aparecer como constitutivas de significados culturales, en lugar de ser su simple extensión o transferencia" (Clifford, 2007:13).

Así, Clifford esboza una experiencia del habitar tanto desde el desplazamiento como desde la inmovilidad. Con esto se quiere decir que el espacio es experimentado y significado tanto por las relaciones fijas, residenciales, como por los viajes que se realizan, sean reales o imaginarios.

Si tomamos al habitar como la relación y adecuación entre el hombre y su entorno en cada una de las escalas territoriales (vivienda, entorno inmediato, barrio, ciudad) evaluadas de acuerdo a su capacidad de satisfacer las necesidades humanas, este concepto se alinea. Por esta razón, es lógico considerar el rol significativo que cumplen los desplazamientos cotidianos en el habitar, a la vez que puede constituirse como un dispositivo teórico-metodológico para comprender el continuo de la vida cotidiana donde se imbrican la vivienda, el barrio y la ciudad a través de estas prácticas. Entonces, lo que interesa en este trabajo no es entender la movilidad en cuanto a movimiento en sí, sino lo que puede develarnos sobre el habitar cotidiano.

\section{POR QUÉ IMPORTA LA MOVILIDAD A LOS FINES DE ESTA INVESTIGACIÓN. JUSTIFICACIÓN DEL PROBLEMA}

Los espacios cartesianos nos permiten localizar personas, objetos y culturas; sin embargo, teniendo en cuenta que las culturas ya no pueden ser localizadas (Kokot, 2007), la espacialización de las identidades fundadas en las coordenadas fijas de los barrios cerrados fijos, ya no tiene gollete. Esta reflexión permite dar paso a otro espacio vivido, experienciado, con connotaciones fenomenológicas.

Para analizar lo diferentes ritmos originados en la ciudad por parte de sus habitantes, nos valemos del ritmoanálisis propuesto por Lefebvre (1992), que surge, no como una planificación consciente y organizada, sino a partir de la mezcla de los habitantes y actividades que se dan en ella. Este involucra, por un lado, la parte temporal de los ritmos, que tiene la capacidad de hilvanar el presente con el pasado y el futuro. Por el otro, lo espacial, que tiene en cuenta la "definición rítmica del lugar, capaz de tener en cuenta los cambios temporales a través de la repetición y la diferencia y de establecer su identidad a base de rasgos rítmicos que persisten a lo largo del tiempo" (Revol, 2012: 13).

Para el análisis hay que sumergirse, observando los ritmos desplegados ante el investigador, pero manteniendo cierta distancia de lo observado para hacerlo (el mismo Lefebvre desde la ventana de 
su balcón). Este, al mirar París desplegándose abajo, se separa del dominio de la ciudad, liberándose de las ataduras a las "calles que lo llevan de un lugar a otro según una ley anónima" (De Certeau, 1996: 104). Pensándolo así, el cuerpo se escinde completamente de la experiencia, lo que haría considerar al espacio solo desde una de sus posibles visiones: la intelectual. Esta concepción ha embelesado a los investigadores de la ciudad quienes, en este sentido han "fragmentado el espacio para estudiarlo con cada uno de sus métodos" (Lefebvre, 1974: 224). Mirar el espacio de esa manera, pensándolo como algo externo y objetivo, susceptible de ser medido precisamente y descrito al detalle, genera una visión de espacio contenido. De la misma manera, históricamente, localizar la observación ha sido un artificio metodológico-epistemológico para la práctica etnográfica (Augé, 1995:1 68). Originalmente utilizada en estudios de pueblos, esta forma de construir objetos de observación fue trasladada al ejercicio antropológico en la ciudad. Desde la Escuela de Chicago (Park, 1984), la tradición de la antropología urbana ha sido apologista de la vida barrial (Caldeira, 2001: 487; Delgado, 1999; Low, 1996; Signorelli, 1999) que decididamente ha volcado su atención a observar barrios o territorios delimitados y cómo en estos se construyen en relación a las vecindades. Esto ha tenido especial difusión en las ciudades latinoamericanas, donde la ciudad es concebida como un conjunto de unidades espaciales homogéneas internamente y diferenciadas entre sí en diferentes dimensiones (etnia, género, ciclos vitales, niveles socioeconómicos); la noción de quartered city (Marcuse, 1997) originando un acuartelamiento espacial respondiendo a la relación entre miedo y alteridad. Visto así, el barrio es la unidad básica preponderante, no solo en cuanto estructura físico-espacial, sino que también dota de sentidos de pertenencia a los habitantes urbanos.

Desde esta posición, este enfoque disciplinar anclado en lo micro social tiene ciertas limitaciones ya que, indudablemente, la experiencia de la ciudad no se restringe al barrio. Pensar los habitantes de barrios cerrados como si estuviesen enclaustrados e inmóviles y que la ciudad, como un campo vasto a ser vivenciado, permaneciendo negado, inexplorado e incomprensible sería necio, teniendo en cuenta la movilidad cotidiana es un recurso fundamental de las personas para llevar a cabo sus actividades cotidianas. Al mismo tiempo, es ineludible que vivir en una ciudad metropolitana, como lo es Córdoba, plantea usos del espacio urbano cada vez más diferenciados, exigiendo desplazamientos. Frente a estos cambios, difícilmente se puede seguir viendo los modos de habitar como algo único, auténtico y con una identidad estática e inmutable.

Concentrar la mirada en el espacio doméstico pone un límite a la reflexión sobre el habitar si es concebido como un conjunto de prácticas y significados bien localizados, solamente contenidos dentro de la vivienda y su entorno inmediato, es decir, en una unidad espacial concreta y con límites fijos.

A partir de lo desarrollado arriba, nace la pregunta sobre si es posible mantener el anclaje del habitar localizado en la casa o siquiera solo en el barrio cerrado. Y dentro de este paradigma, la pregunta planteada al principio del trabajo ¿dónde buscar el sentido de la experiencia urbana del habitar cuando se vive en un barrio cerrado? puede ser respondida intentando "asilvestrar" el espacio de la ciudad, en lugar de pensarlo cuantitativa, geométrica y matemáticamente.

Comprender que los habitantes de los barrios cerrados no agotan su existencia en su vivienda, entorno inmediato o barrio no vino sin sus complicaciones. A los fines de este trabajo parecía que los temas iban a ser inabarcables, al igual que la complejidad de los modos de habitar. Por esta razón, se plantea este escrito como la exploración de una punta de la línea para comprender la complementariedad y extensión que proponen los desplazamientos cotidianos al espacio doméstico, foco de este estudio. y es por ello que se requiere indagar junto a otras perspectivas teórico-metodológicas que provean de nuevas claves de comprensión.

De esta manera, se comienza a tener en cuenta las movilidades como algo más que moverse de un punto a otro, cuestionando el transporte desde una noción meramente instrumental. Esta concepción las vincula con un espacio no estático (Iturra, 2015). Los lugares obtienen nuevos significados si contemplamos el cambio de un espacio fijo con significado a un espacio móvil con múltiples significados simultáneos (Jirón, comprender...). Tomar las movilidades cotidianas como práctica, como experiencia y como dispositivo de observación, se convierte en un recurso para 
conocer las implicaciones que tienen en la forma en que las personas habitan la ciudad, entendiéndola también como una forma de producción de espacio urbano.

Es decir, que no se intenta comprender lo metropolitano desde la vivienda, sino observar, develar y analizar las experiencias múltiples y multiformes en que los habitantes espacializan sus cotidianeidades durante las conformaciones del trayecto que admiten que el espacio vaya siendo significado.

Teniendo en cuenta lo descrito arriba, para entender al habitante y las relaciones que establece con los espacios que vivencia, la antropología es un campo disciplinar cuyas herramientas son de gran utilidad y la utilización de la práctica etnográfica permitió desplegar múltiples lugares de observación. La pregunta ¿cómo habita alguien de un barrio cerrado? Implica comprender no solo cómo viven los sujetos, sino la complejidad de sus experiencias espaciales en la vida cotidiana y las implicancias que tienen para la conformación de sus identidades.

\section{METODOLOGÍA. LA RECONSTRUCCIÓN DEL VIAJE}

Pensando las movilidades urbanas como un recurso para conocer cómo habitan las personas de barrios cerrados de la ciudad de Córdoba, entendiendo el habitar como una forma de producción de espacio urbano, se definió un modelo metodológico que organiza el trabajo de campo en cuatro momentos. Lo primero fue seleccionar los casos. El segundo momento implica el proceso de diseño y aplicación de instrumentos. El tercero detalla cómo se producen los relatos etnográficos, mientras que el último se concentra en el análisis.

\subsection{LOS CASOS}

Se contactó a personas que ya habían participado en el estudio con el propósito de seguir explorando la forma de habitar de esas personas con quienes ya había hecho algunas aproximaciones. Al mismo tiempo, evitaba comenzar otro proceso de búsqueda de participantes que aceptasen un encuentro. Finalmente, se eligió intentando que diferentes zonas de la ciudad fuesen representadas. Pero los casos no se agrupan por sector urbano, ni por ninguna característica.

No es significativo el barrio del que son en sí, ni las distancias recorridas. El énfasis está en develar el repertorio de prácticas de movilidad en la ciudad, cómo se significan y profundizar el conocimiento de quienes viven en barrios cerrados habitan utilizando la movilidad.

Cada persona participante en la investigación fue considerada como un caso; una unidad etnografiable independiente de otras. Estos los constituyeron dos mujeres: una de un barrio cerrado de zona norte y otra del área metropolitana cuyas movilidades cotidianas transcurren en la ciudad de Córdoba. Se incorpora un tercer caso, que es un hombre que habita en un barrio cerrado de la zona sur de la ciudad. Los tres casos están en diferentes estadios de ciclo de vida y poseen diferentes ocupaciones, grupos familiares, etc.

Se optó por esta cantidad de casos porque sería imposible en términos prácticos asumir una investigación de esta magnitud individualmente. Además, esta etapa se enfoca en lo exploratorio.

En el presente trabajo se desarrolla con uno de los casos en los que se ha podido usar estos instrumentos a los fines de la extensión del escrito y de enfocarnos sobre los temas que se querían trabajar en este texto.

\subsection{DISEÑO Y APLICACIÓN DE LOS INSTRUMENTOS EN CAMPO Y EN GABINETE}

En este apartado se desarrollan el segundo y tercer momento de la construcción de datos en el campo. 
La estrategia metodológica incorpora técnicas de entrevista, observación directa y participante y la técnica de sombreo que se registra en el cuaderno de campo y con dispositivos fotográficos y audiovisuales, en este caso, el celular.

Los momentos del trabajo de campo consistieron, primero, en una entrevista. Esto se decidió porque el habitar dice sobre el individuo que habita en algún espacio y en el proceso de contarlo (raccontare), el proceso es expresado por la forma en que el individuo habita el espacio y es habitado por él (Vitta, 2003). La entrevista es en profundidad con preguntas semi estructuradas donde se establecían las prácticas de movilidad, los lugares, los tiempos, las vinculaciones con la rutina y la vida cotidiana. A su vez se asentaban las dinámicas de trabajo, de compras, de estudio, de esparcimiento, entre otras asociadas a sus lugares y temporalidades. Se indagó sobre la trayectoria residencial en el barrio cerrado y en otros lugares de la ciudad, estableciendo comparativas. Se preguntó por valoraciones propias acerca de su movilidad diaria y los lugares significativos en sus desplazamientos y las razones.

Durante las entrevistas, puede construirse una narrativa en la que no solo se tiene en cuenta "lo dicho" por la persona entrevistada, sino que se observa y se registra la experiencia de la práctica. En el espacio doméstico, esto es más fácil, porque uno puede presenciar muchas de ellas en el mismo lugar en el que transcurren. Sin embargo, para conocer las experiencias de la movilidad urbana, solamente podíamos valernos de lo expuesto en la entrevista.

Por esta razón, la complementamos con la metodología antropológica del trabajo de campo, que se fundamenta en el conocimiento directo del objeto de estudio, donde se intenta alcanzar una visión desde dentro de lo que estudia. Como ya mencionamos, en el ámbito de la vivienda, observando el habitar doméstico, el propio espacio se constituye como objeto de estudio, a la vez que nos delimita la investigación. Los límites del objeto de estudio (el espacio arquitectónico) y los límites del campo (el espacio de investigación) coinciden. Los mismos espacios que se habitan son los que marcan la pauta de investigación, ya que se observa y registra la experiencia de la práctica creando una narrativa a la vez que es una forma de construir conocimiento acerca de la experiencia. Por su condición de proceso humano, anclado en la experiencia de estar en el mundo (Imilan e Iturra, 2014), estas narrativas de movilidad deben ser construidas desde donde son producidas, en el trabajo de campo. Por esto, el seguimiento de los habitantes durante sus prácticas de movilidad cotidiana, puede develar ciertas novedades sobre su habitar. Entonces, se retoma de los estudios del equipo de investigación de Paola Jirón en Chile, la técnica del sombreo, aplicada para capturar experiencias de movilidad cotidiana urbana utilizando el transporte público Transantiago (Jirón, 2007a; 2010).

De acuerdo a esta autora, el sombreo consiste en una forma de acompañamiento individual acordado con los participantes de la investigación durante todas las etapas de sus trayectos de movilidad de una jornada cotidiana. Esta herramienta provee un enfoque etnográfico multisituado y en movimiento que permite describir las experiencias de movilidad y las prácticas cotidianas de ocupación del tiempo y el espacio (Jirón, 2009).

Esta herramienta fue un momento central de trabajo de campo. Implica observar en profundidad las interacciones sucedidas en el espacio y el tiempo que son reveladas durante los recorridos diarios. Por interacciones, la autora entiende que son los eventos significativos para las personas antes, durante o después del viaje. Estos comprenden el amplio abanico de relaciones entre cuerpo (gestualidad, emociones, sentidos, vestimenta, movimientos), espacialidad (materialidades, objetos, entorno físico, equipamientos, colores, texturas, circulaciones, aspectos ambientales, estructuras, formas), otros sujetos relevantes en el viaje, estrategias de viajes que van adoptando (corta o larga duración, individuales o grupales) y procesos de significación que se le da a cada espacialidad que se va generando. Este conjunto heterogéneo y de múltiples dimensiones componen la experiencia de la movilidad cotidiana urbana y cuyo trayecto termina emergiendo a través de su representación con diferentes métodos de registro.

Durante todo el día, se acompaña al participante desde el momento que deja su vivienda hasta que regresa, construyendo un relato mediante la conversación con el entrevistado, textos en la libreta de campo e imágenes (sean dibujos, fotografías o videos). 
Estos instrumentos no siempre fueron aplicados en su totalidad, ni en un orden específico. Fue ponderada la flexibilidad y considerar cada caso como único para obtener mejores resultados durante el levantamiento de la información en campo. Esto permitió adecuarse a los tiempos y las interacciones con las personas y cotejar las diferentes reacciones y experiencias según se iban sucediendo los eventos.

En una segunda instancia, se produce un relato etnográfico de cada uno de los casos de estudio complementados con los otros materiales de registro, diagramas, fotografías, dibujos y/o videos.

Por su carácter etnográfico, el periodo de observación y la densidad del registro los caracterizan. En este caso, la unidad temporal del relato es un día de duración y posee un inicio, un fin y una progresión interna que involucra tanto los elementos de la experiencia de movilidad del participante y del investigador, sean registrados durante el sombreo o aquellos que hayan surgido a raíz del trabajo con diferentes instrumentos, diagramas, fotos, entrevista, devolución y discusión con el participante sobre el relato.

En los tres casos concertó una reunión para entregar una devolución de los registros.

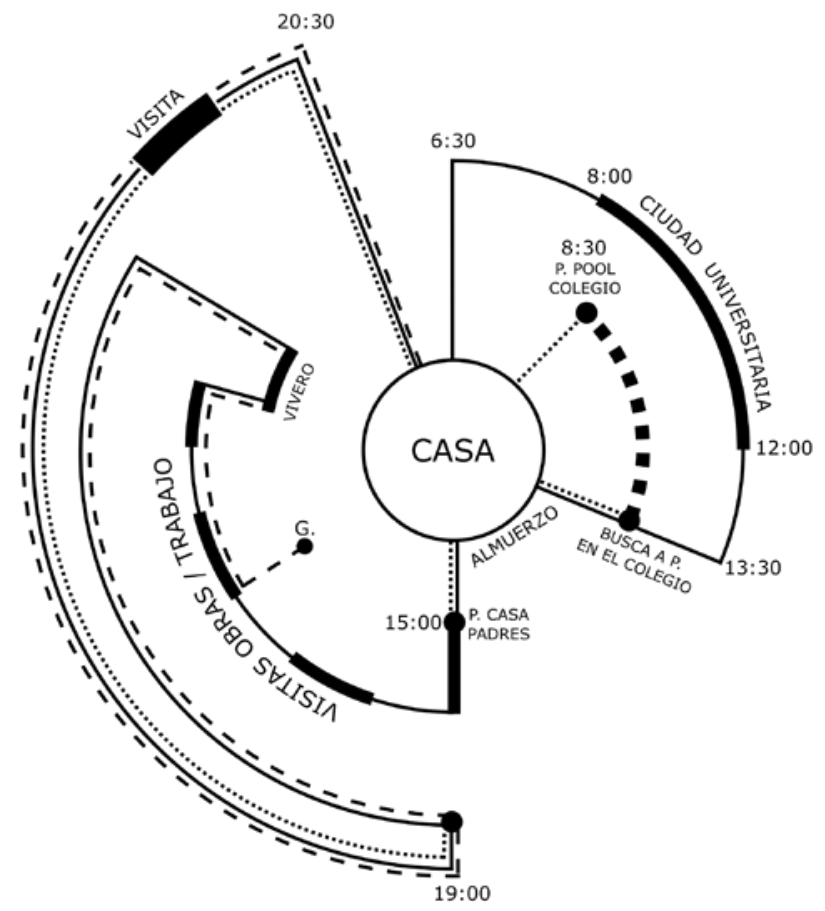

Diagrama de los movimimientos de $\mathrm{P}$ en la ciudad. Fuente: elaboración propia.

\begin{abstract}
Además del relato etnográfico, la herramienta más utilizada para sistematizar y comunicar las experiencias de registro fue la construcción de diagramas cualitativos. Fueron construidos posterior al sombreo e iban siendo complementados con otro tipo de información que aparecía en el transcurso de las entrevistas. La evolución de la serie de dibujos a raíz de cada nueva información que iba apareciendo en la historia del participante facilitó expresar el fenómeno de un modo más fiel, a diferencia de una ilustración, que intenta restituir el fenómeno íntegramente, afectando su legibilidad (Vitta, 2003). El uso de diagramas admite que, desde el espacio cartesiano, usualmente utilizado para representar cartográficamente, localizando grupos y objetos, de lugar a un espacio vivido, experimentado y significado.
\end{abstract}

\subsection{LA FORMACIÓN DE LAS RUTAS (DE SENTIDO)}

En este apartado se incorporan fragmentos del relato etnográfico de una de las participantes.

\section{P: "Todo el día en la calle"}

P tiene 50 años, estudió arquitectura en Córdoba y trabaja independientemente especializada en espacios exteriores, particularmente, diseño y obra de jardines residenciales.

El día que se realizó el sombreo, $\mathrm{P}$ tiene como tareas hacer el seguimiento de varias obras que ella proyectó y lleva adelante la dirección ejecutiva, además de dar clases en la facultad.

Llegué a su casa en colectivo, me bajé y tuve que caminar más de 40 minutos para llegar.

$P$ sale de su casa muy temprano, a las 6.30 dejando a su hijo de 7 años en la casa en compañía de L, su empleada cama adentro, desayunado y preparado para que el "pool" lo pase a buscar para ir 
al colegio. Viven en un barrio cerrado de La Calera desde hace cinco años, aunque $\mathrm{P}$ reconoce que "sólo llega a dormir a su casa", su vida transcurre "todo el día en la calle" afirma. Usa un sweater celeste que se sacaría a los cinco minutos y lo tiraría en el fondo del baúl hasta el final del día. El calzado es cómo dice ella, prioriza la comodidad, teniendo en cuenta que tal vez tenga que estar pisando tierra, más que caminando. La hora pico para "entrar" a la ciudad todavía no llega, lo que le permite hacer el recorrido a Ciudad Universitaria de forma cómoda y fluida. Durante el camino escucha la radio, es el momento del día en que aprovecha y "soporta" para "no estar desactualizada". A los cinco minutos de viaje, recibe su primera llamada por teléfono de un cliente que tenía que ver ese mismo día. Las charlas con ella son interrumpidas varias veces por otras llamadas, breves, pero incesantes. Tiene un dispositivo con ventosa para tener siempre el teléfono a la vista frente a los ojos.

Pasando El Tropezón, el sol comienza a salir e ilumina y calienta el interior del auto con una luz amarilla. El sol nos pega de frente. P inicia una serie de microcoordinaciones. Llama a cada una de las personas conque debería juntarse durante el día. Son cinco personas e ir a un vivero a hacer unas compras y otros trámites personales. Todos en lugares de la ciudad y horas distintos.

$\mathrm{P}$ dice que antes de salir de su casa ya ha trazado un mapa mental de cómo tiene que ser el recorrido, calculó los tiempos de desplazamiento y el tiempo que permanecería en cada lugar para poder coincidir con la presencia y horarios de, no solo sus comitentes, sino de los momentos en que tiene que estar en la obra.

Una hora después de haber salido de su casa, P llega a Ciudad Universitaria donde da clases dos veces por semana. Al mediodía, la clase termina y $\mathrm{P}$ se dirige de nuevo hacia su auto para emprender el camino a buscar a su hijo al colegio que queda a "cuatro o cinco cuadras" de donde viven. Antes de hacerlo, pasa por una verdulería en Calera, un zapatero donde había dejado calzado para arreglar, la pollería y un mercado para comprar tres o cuatro ítems de necesidad. $\mathrm{P}$ hace el esfuerzo de dejar siempre estacionado su auto en la puerta de los locales para estar expuesta al calor lo menos posible.

$\mathrm{P}$ busca a su hijo del Colegio a las 13.30. Entra en el auto gritando y $\mathrm{P}$ le dice que haga silencio, ya que se encuentra al teléfono organizando el primer encuentro con sus clientes. Comen los tres en la casa después de que $L$ haya preparado el almuerzo y $P$ haya buscado una cartera de cuero grande para meter todos los papeles, archivos, documentos que requiere para el día, la tablet y enseres necesarios para poder trabajar. Incluso guarda unas cuantas barras de cereal para ella y para su hijo si "se pone pesado".

Dice que aprovecha que tiene algunas obras en zona sur para llevar a $\mathrm{P}$ a la casa de sus padres en barrio Observatorio para que lo cuiden mientras todavía no empieza sus actividades por la tarde.

El primer encuentro se realiza en un barrio cerrado de zona sur. La obra está terminando y necesitaba cobrar un dinero, de modo que la visita fue corta. En apenas diez minutos chequeó los estados de finalización y habló con el dueño de la casa. En el auto saca su carpeta y confirma su próximo encuentro, ahora en el barrio General Paz. "En veinte minutos nos encontramos en la puerta de se casa". Cuando cuelga revisa los papeles y los ordena para tenerlos listos para cuando llegase al lugar. Durante el camino la llama su hijo a través del teléfono de sus padres simplemente para saber cómo va su día y para avisarle que un amiguito suyo del barrio iría a la casa de sus padres para después volver con el al barrio. P mira su reloj y exclama: “¿Por supuesto! En tres horas nos vemos".

Llegamos con precisión al encuentro en General Paz donde la dueña de la casa ya nos estaba esperando en la puerta con los portones abiertos de par en par para que P entre su auto. Esta vez, $\mathrm{P}$ tarda más de media hora haciendo el relevamiento de plantas que necesitaban para la próxima etapa de la obra. Hace calor y el sol de la siesta la instiga a hacer las cosas lo más rápido posible me dice. El próximo encuentro no es lejos de donde nos encontramos, así que vamos caminando tranquilamente y buscando de los lados dela vereda con sombra para que P pueda cobrar un dinero. Después de eso, $\mathrm{P}$ recibe una llamada que le confirma que uno de los encuentros se cancela. 
"Yo estoy muy expuesta todo el día acá en el auto". Se refiere a la inseguridad, a los choques, al granizo, a quedarse dormida al volante, "a todo".

Más tarde, sin que me haya avisado, $\mathrm{P}$ detiene el auto en el centro y comienza a hacer varias llamadas, pregunta precios, stock, tiempos de entrega, ... hasta que una señora se acerca a nosotros alegremente. Es $\mathrm{G}$ una compañera de trabajo de la facultad quien vive en un barrio cerrado donde $P$ justamente tiene que ir a trabajar esa misma tarde. Luego de un par de minutos de charla, $P$ arranca el auto y vamos a un vivero cerca de circunvalación. Realiza sus pedidos y vuelve al auto quejándose por el calor abrasador.

G, P y yo vamos a tomar un café, como es usual para ellas hacerlo ese día de la semana. Nos sentamos afuera a pesar del calor.

P llama a su hijo para decirle que ya está lista y volvemos a barrio Observatorio a buscarlo con su amigo. $\mathrm{P}$ baja del auto y me pide que la espere con $\mathrm{G}$ en el auto para poder hablar algunas cosas con sus padres. A los diez minutos vuelve con su hijo y un amigo.

Los cinco el en auto emprendemos el viaje a zona norte por la Duarte Quirós. El paisaje va cambiando, las edificaciones se hacen más bajas, los comercios de escala más chica, la vegetación aparece distinta y la línea de horizonte cambia. No solo por la profusión de construcciones que va cambiando, sino porque subimos de cota. Pasamos El Tropezón y el paisaje cambia por completo. De un lado, los cercos altísimos y la vegetación adyacente de los barrios cerrados y terrenos cercados. Del otro, suelo ¿rural?

P charla con G, mientras los dos niños pelean en el auto. P: “¿Quién quiere escuchar música?”. Los dos niños cantan y permiten que $P$ y $G$ (quien va sentada adelante) sigan conversando. Los autos que nos cruzamos son pocos y algunas personas hacen ejercicio corriendo al lado de las rejas de los barrios cerrados.

Paramos en una casa del Cerro dos minutos. P ni siquiera entra en la casa. Habla con su dueño parada en la puerta. Sube al auto, revisa nuevamente su carpeta de papeles y partimos a Cinco Lomas. Es un barrio con mucha topografía. Dejamos a $\mathrm{G}$ en su casa y seguimos con el auto tres o cuatro cuadras subiendo y bajando hasta la casa. El patio es grande y $P$ menciona que están haciendo el replanteo de la obra. Estaciona el auto en el borde de una calle de tierra frente a la casa y me pide que me quede con los niños en el auto. Se portan bastante mal. El hijo de $P$, después de esperar media hora, pierde la paciencia y se pasa al asiento de adelante y se pone a tocar bocina. La llamada de atención no es efectiva, ya que $\mathrm{P}$ tarda quince minutos más en volver al auto. Se revisaron las anotaciones que registraban actos cotidianos como el aburrimiento al momento de hacer compras o la ansiedad de dejar a los niños a tiempo en el colegio, el temor de llegar a casa tarde por la noche, entre muchas otras actividades cotidianas.

Ya son cerca de las ocho de la noche y volvemos a su barrio, que queda a pocos minutos en auto de allí. P expresa la importancia de su auto para moverse. No solo por la ciudad, sino dentro de los barrios cerrados, donde trabaja principalmente. Menciona también que es una herramienta para llevar cosas, desde las compras para los clientes, a insumos para ella.

\section{CONCLUSIONES.}

\subsection{SOBRE $P$}

Se presentan algunas reflexiones finales que intentan dar cuenta de las propias rutas, espacios y tiempos involucrados a partir del relato etnográfico de $\mathrm{P}$, que colaboran a la comprensión de la relación entre movilidad y hábitat residencial.

La apropiación y significado del espacio ampliado por fuera del barrio cerrado no encaja exactamente con la idea de habitar o identidad barrial, pero sí con la experiencia del habitar de sus habitantes. Por ello, conocer cómo se hacen lugar los espacios fijos y móviles y cómo se apropian de ellos los habitantes se presenta como una forma alternativa de pensar la articulación del hábitat, los habitantes y el habitar. Para ello, se incorporan perspectivas de tiempo-espacio que, más que 
dejar de lado los espacios físico-materiales, los incorpora en relación con su habitante, observando que cambian a medida que son vividos.

Esto se refleja en una primera aproximación a la trayectoria de $\mathrm{P}$ era que su espacialidad no estaba contenida dentro de un solo lugar. Ni siquiera su espacio laboral, siendo arquitecta especializada en espacios exteriores. En este sentido, el relato de $\mathrm{P}$ resulta clarificador acerca de cómo la experiencia de su casa y barrio no dicen mucho sobre su habitar la ciudad y viceversa, si no que se que observan que el continuo de su vida cotidiana que transcurre en diversos lugares de la ciudad.

$\mathrm{P}$ nos permite también pensar la relación que tienen muchas personas de Córdoba con la ciudad cuando expresa "Yo no estoy nunca en casa". Esto se puede explicar desde las dinámicas de trabajo, donde las casas pasan a tener un papel de apenas dormitorios para muchos. También manifiesta un debilitamiento del barrio como espacio de adscripción identitario, producto de la erosión de los lazos sociales que se sostenían por la solidaridad y prácticas comunitarias.

Para P su casa y barrio no juegan un rol relevante en su vida diaria, ella habita la ciudad trabajando en la movilidad. Por esta razón, $P$ tuvo que desplegar una serie de tácticas para poder realizar sus actividades diarias que requerían de gran coordinación denotando el conocimiento que $P$ tiene de la ciudad para conocer cuánto tiempo le lleva ir de un lugar a otro y cuáles son las rutas más adecuadas para evitar el alto tráfico. Esto da cuenta de dos habilidades que tuvo que incorporar a sus prácticas cotidianas de movilidad: por un lado, aprender a viajar y aprender a evadir. $\mathrm{P}$ tuvo que entrenarse en el conocimiento de la ciudad para saber cuánto tardaba en atravesarla e, indefectiblemente, llegar a tiempo a sus encuentros.

Las características de su trabajo flexible y cíclico transforman la totalidad de ciudad en su "lugar de trabajo" mientras se mueve por ella. Así, la multiplicidad de actividades y la cantidad de las horas que pasa en el auto, hicieron que para $P$ sea una "extensión de su casa", por lo que fue completamente natural para ella que la entrevista se llevase a cabo durante alguno de los trayectos en el auto, ya que lo consideraba una parte de su oficina. El habitar como proceso dinámico cuestiona la rigidez de los límites y escalas del espacio del hábitat residencial cuando vemos que, a través de la movilidad cotidiana, se desafían sus las demarcaciones y jerarquías. Estos límites difusos y cambiantes según el día y en función de las practicas de los habitantes implican preguntarse sobre la utilidad de determinar a priori los bordes de un espacio vivido, aunque sea como decisión metodológica. En este sentido las escalas del hábitat residencial (vivienda, entorno, barrio, ciudad), producto de los cambios socioespaciales, son muy difíciles de desarticular, ya que la mayoría de las personas las viven como un continuum de espacios relacionados a partir de la experiencia cotidiana.

Una tercera habilidad se suma el aprender a utilizar los tiempos de espera o de traslado. El acceso a un aparato tecnológico, celular con internet, tiene un rol central para la conformación de su oficina móvil. La masificación de tecnologías ha permitido deslocalizar el trabajo, pero más que la disolución del lugar de trabajo, estos se han diversificado, conquistando incluso la movilidad como lugar laboral.

Por último, se observa que su mundo privado se entrelaza con el laboral, desarrollándose casi de forma paralela a su vida laboral, como se podría interpretar por la presencia de su hijo física y telefónicamente en el transcurrir del día, o los encuentros con su amiga. Esto nos da una pauta de que la ciudad se experimenta a través de las diferentes vinculaciones de las esferas laboral e íntima de una manera continua y fluida, cuyos límites no son tan estrictos.

El relato de $\mathrm{P}$ nos ayuda a comprender cómo la experiencia en su vivienda y barrio no nos da mucha información sobre cómo habita la ciudad. Sin embargo, pensando en lo desarrollado arriba, da cuenta de cómo las diferentes esferas de su vida cotidiana transcurren en un continuo que se desarrolla en numerosos lugares de la ciudad involucrando actividades tanto de índole personal como laboral. Observamos una flexibilidad en cuanto a los tiempos y lugares de trabajo. El tiempo productivo y el tiempo no productivo adquieren una plasticidad que diluye la frontera entre los tiempos productivos de los no-productivos. Los tiempos de descanso y familiares tienden a fusionarse con el tiempo de trabajo, insertándose las prácticas laborales con las de la vida privada. Esto significa que, si pensamos que donde hay un tiempo siempre hay un espacio, la existencia de 
un tiempo flexible, involucra un espacio plástico. Al debilitarse estas distinciones, es lógico que también haya mayor dificultad de identificar tanto nuestros horarios como nuestros lugares de trabajo, entre otras prácticas cotidianas.

\subsection{LAS HUELLAS QUE NOS DEJAN LAS RUTAS}

Tal como puede desprenderse de los autores anteriormente reseñados y las observaciones propias, comprender la urbanidad puede constituir un importante aporte y aliciente para la conformación de una nueva cultura urbanística donde los ritmos de las ciudades sean una dimensión clave de la vida social. Esto implica dejar de lado la idea de que las ciudades son un objeto científico abstracto, sino producto del trabajo cotidiano de la sociedad, siendo moldeada y remodelada por los diferentes agentes sociales que lo disputan y se lo apropian material y simbólicamente en cada momento histórico.

En ese marco nos propusimos analizar las formas de apropiación del espacio urbano, entendiendo las prácticas como parte constitutivas que se ponen en juego en la movilidad. Se trata, entonces, de comprender la articulación entre la dinámica de la estructura del espacio social cordobés y las formas diferenciales de apropiación del espacio urbano que despliegan sus habitantes, focalizándonos en el espacio vivido que las personas ponen en juego para desplegar sus prácticas y el mundo social.

Pensar el hábitat residencial de quienes viven en barrios cerrados utilizando una perspectiva que incluya la movilidad, genera una posibilidad de conceptualizarlo relacionando el hábitat, los habitantes y su habitar. Tal como se expresa en la introducción, el presente trabajo propone que, a pesar de su escasa relevancia en los procesos de desarrollo urbano en general, es un espacio interesante de oportunidades y desafíos para el desarrollo de la antropología urbana en Córdoba.

El transcurso de esta etapa de la investigación tuvo dos retos:

Primero, reconocer que un enfoque centrado en el espacio percibido de la ciudad y las dimensiones más evidentes de las prácticas espaciales-materiales, transformadas en lo único real a ser estudiado, explicado y atendido por las políticas públicas, la planificación urbana y las ciencias sociales y espaciales, era insuficiente. Si todo lo que subyace esta concepción de espacialidad centrada solo en lo visible es considerado como anecdótico e invisibilizado por ser considerado intrascendente para la teoría y la práctica de la ciudad, pensar en este abordaje fue una gran oportunidad

Por otro lado, retomamos una crítica recurrente se asienta en que aquellos que planifican e intervienen la ciudad tienen una vinculación escasa o nula con quienes la habitan, transforman y crean cotidianamente (De Certeau, 1986; Lefebvre, 1972). En este tono, Jensen (2013) plantea que se construye tanto desde el diseño y planificación urbanos como desde la forma en que se vive el espacio urbano, de modo que un acercamiento "desde el punto de vista nativo" (Geertz, 1990: 168) sería idónea. En este sentido, la antropología como campo disciplinar plantea un acercamiento donde las situaciones vividas, cuyo carácter es profundamente dinámico, cualitativo y fluido, son un insumo inexorable e insustituible para levantar datos que se involucran directamente con las experiencias y prácticas sociales de los habitantes urbanos. Así, se entiende que el objeto de estudio desborda los límites disciplinares donde converjan las ciencias sociales y amplié otros ámbitos de conocimiento como la arquitectura y el urbanismo, entre otras.

También implicó pensar sobre los modos más adecuados para capturar las interacciones experienciales significativas en el tiempo-espacio de la movilidad. Así, se requiere avanzar hacia enfoques teórico-metodológicos más críticos, comprensivos y reflexivos sobre estos procesos para promover la observación, la visibilidad y el reconocimiento de aquellas dimensiones socio- culturales fundamentales para el desarrollo de las ciudades. El uso de la etnografía supuso un enriquecimiento en la exploración de prácticas de movilidad y contribuir a las discusiones sobre las metodologías cualitativas en los estudios urbanos. Por otro lado, fue la integración interdisciplinaria de la etnografía a las perspectivas del urbanismo y la arquitectura para abordar las preguntas de investigación. Esta articulación interdisciplinar propuso un reconocimiento a la urbanidad en la conformación del campo de conocimiento urbano y su importancia para incorporar activa y 
participativamente a los habitantes urbanos en dichos procesos, a través de dispositivos teórico metodológicos que permitan avanzar hacia un mayor conocimiento y vinculación con los habitantes urbanos incorporando la amplia diversidad de comunidades. En tal sentido, se cuestiona la influencia hermética que muchas veces tienen los grupos de expertos, contribuyendo a una mayor interacción entre la racionalidad técnica característica de los urbanistas tradicionales con una creciente visión en las prácticas de los habitantes urbanos, favoreciendo una perspectiva más abierta y flexible que las que hoy predominan.

En este sentido, la voluntad de reconocer y echar luz sobre nuevas maneras de pensar y hacer en las sociedades urbanas contemporáneas, establece una pregunta siempre abierta que no se debe ignorar, aunque a veces nos resulte un tanto ajena, ya que alude no solo a la producción de conocimiento sino a los ámbitos de decisión política sobre las urbes.

La línea todavía no está trazada y los lugares seguros para la reflexión todavía no existen. Sin embargo, en el conjunto de afirmaciones y pensamientos que se han expuesto hasta ahora hay tanto reflexiones de orden teórico como su correlato empírico que evidencian que no solo que es un tema que merece ser revisitado y repensado a la luz de la experiencia urbana, sino que es de fundamental importancia para pensar en cómo trasformaciones de orden socio-espacial se imbrican en la producción de experiencias e identidades en la ciudad, que siempre tienen su correlato con el habitar.

\section{BIBLIOGRAFÍA}

ARIZAGA, M. C. (2004). Espacialización, estilos de vida y clases medias: procesos de suburbanización en la RMBA. En Perfiles Latinoamericanos, Revista de la FLACSO, Sede Académica México, Año 12, Nro. 25, 43- 58.

AUGÉ, M. (1995). Hacia una antropología de los mundos contemporáneos, Gedisa, Barcelona.

CALDEIRA, T. (2001). City of Walls. Crime, Segregation, and Citizenship in São Paulo, University of California Press, Berkeley, Los Ángeles y Londres.

CLIFFORD, J. (1997). Itinerarios transculturales, Barcelona, Gedisa.

CZARNIAWSKA, B. (2007). Shadowing, and Other Techniques for Doing Fieldwork in Modern Societies, Slovenia, Korotan Ljubljana.

GARCÍA CANCLINI, N., CASTELLANOS, A. y MANTECÓN, A.R. (1996). La ciudad de los viajeros. Travesías e imaginarios urbanos: México, 1940-2000. Colección Antropología México: UAM / Grijalbo.

DE CERTEAU, M. (1996) La Invención de lo Cotidiano. 1 Artes de Hacer. Universidad Iberoamericana, Instituto Tecnológico y de Estudios Superiores de Occidente, Centro Francés de Estudios Mexicanos y Centroamericanos, México, D.F.

DELGADO, M. (1999). El Animal Público. Hacia una antropología de los espacios urbanos, Anagrama, Barcelona.

DONZELOT, J. (1999), La Nouvelle question urbaine, Esprit, núm. 258, París.

GEERTZ, C. (1990). El antropólogo como autor, Paidós Ibérica, Barcelona.

IMILAN, W. (2007). La ciudad etnografiable: El problema del objeto en Londres, Chicago y Santiago de Chile. Serie Documentos.

IMILAN, W. e ITURRA, L. (2014). Narrativa visual del paisaje migrante: Aproximaciones desde la etnografía y el video como herramientas de exploración urbana. Revista 180, 18 (34): 10-15.

IMILAN, W. y LANGE, C. (2003). Aproximación a la antropología urbana chilena y el trabajo de campo en la ciudad. En Richard, N. (ed.), Movimiento de campo. En torno a cuatro fronteras de la antropología en Chile (pp. 27-44). Guatemala, ICAPI.

INGOLD, T. y VERGUNST, J. L. (2008). Ways of walking: ethnography and practice on foot. Hampshire-Burlington, Ashgate.

ITURRA MUÑOZ, L. (2015). El uso de la fotografía para problematizar lo urbano. Transferencias metodológicas, etnografía visual en la enseñanza de arquitectura. Revista de Arquitectura, 19(28), Pág. 22-30.

JIRÓN, P. A. (2007a). Place making in the context of urban daily mobility practices: actualising time-space mapping as a useful methodological tool. En Huijbens, E. \& Páll Jónsson, Ó. (eds.), Sensi/able spaces, Newcastle: Cambridge Scholars Publishing. (pp. 228248).

(2007b). Implicancias de Género en las experiencias de movilidad cotidiana urbana en Santiago de Chile. Revista Venezolana de Estudios de la Mujer. Vol. 12, No 29, pp. 173-197. Caracas

(2009). Prácticas de Movilidad Cotidiana Urbana: Un Análisis para Revelar Desigualdades en la Ciudad. En Espacios, Prácticas y Cultura Urbana, M. TIRONI y F. PÉREZ (Comp.): 176-189. Santiago de Chile: ARQ Ediciones. (pp. 36-53)

(2010). On Becoming 'La Sombra/the shadow'. En Mobile Methods, BÜSCHER, M. URRY, J. \& WITCHGER, K. London, Routledge 
(2012) La importancia de la experiencia de movilidad en la planificación del transporte. Aprendizajes de Santiago de Chile, en J. D. DÁVILA (comp.), Movilidad urbana y pobreza. aprendizajes de medellín y Soacha, Colombia, University College London/Universidad de los Andes, Bogotá, pp. 23-30. Recuperado https://www.bartlett.ucl.ac.uk/dpu/metrocables/book/Davila_2012_Movilidad_urbana_y_pobreza_UCL_UNAL.pdf>.

JIRÓN, P. y LANGE, C. (2017). Comprender la ciudad desde sus habitantes. Relevancia de la teoría de prácticas sociales para abordar la movilidad. Cuestiones de Sociología, 16, e030.

JENSEN, A. (2011). Mobility, Space and Power: On the Multiplicities of Seeing Mobility. Mobilities, 6 (2), $255-271$.

(2013). Staging Mobilities. Londres: Routledge.

KOKOT, W. (2007). "Culture and Space - anthropological approaches". Ethnoscripts, 9(1), 10-23.

LANGE VALDÉS, C. (2015). Comprender la Urbanidad. Oportunidades y desafío de la antropología Urbana en el marco de la política nacional de desarrollo Urbano. Revista Antropologías del Sur, 3, pp. 137 - 154

LEFEBVRE, H. (1969). El derecho a la ciudad. Barcelona: Ed. Península.

(1972). La vida cotidiana en el mundo moderno, Madrid, Alianza.

(1974). La producción del espacio. [En línea]. Papers, Revista de Sociología. (3): 219-229, 1974. ISSN 2013-9004. Disponible en: http://pa- pers.uab.cat/article/view/v3-lefebvre/pdf-es

(1976). Espacio y política: el derecho a la ciudad, Barcelona, Península.

(1992). Ritmoanálisis. Espacio, tiempo y vida cotidiana, Nueva York, Continuum.

LOW, S. M. (1996) The Anthropology of Cities: Imagining and Theorizing the City. En Annual review of anthropology, núm. 25, pp. 383-409. Recuperado en: <http:// www.jstor.org/stable/2155832>.

MARCUSE, P. (1997). Notes for Copenhagen, mimeo cortesía de la Universidad Torcuato Di Tella.

MASSEY, D. (2005). For space, London, Sage.

PARK, R. (1984). The City. Suggestions for the Investigation of Human Behavior in the Urban Environment. En Robert E. Park, Ernest W. Burgess y Roderick D. Mckenzie (eds.), The City, The University of Chicago Press, Chicago, pp. 1-47.

REVOL, C. (2012). Rue Rambuteau Today: Rhythmanalysis in practice en Urban, NS02, pp 3-14.

SIGNORELLI, A. (1996). Antropología Urbana, Ed. Antrophos-UNAM, México.

SENNETT, R. (1976). Vida urbana e identidad personal. Los usos del desorden, Barcelona, Península.

SERRES, M. (1988). Topologías. En Lévi-Strauss, C. (Ed.). La identidad. Barcelona: Petrel. (pp.115-132)

SOJA, E. W. (2000). Postmetropolis; Critical Studies of Cities and Regions, Blackweil, Oxford.

VITTA, M. (2003). El sistema de las imágenes: Estética de las representaciones cotidianas, España, Paidós.

URRY, J. (1990). The Tourist Gaze. Leisure and Travel in Contemporary Societies, Sage, Londres, 2002'. Venturi, Marco (ed.). Grandi eventi. La festivalizzazione delta política urbana, II Cardo, Venecia, 1994. Vilagrasa. Joan. Centre historie i activitat comercial a Worcester, 1974-1988. Un estudi de morfología urbana, Departament de Geografía i Historia, Facultat de Lletres de l'Estudi General de Lleida. Lleida. 